\title{
BMJ
}

\section{Effects of vitamin D supplementation on bone density in healthy children: systematic review and meta-analysis}

\author{
Tania Winzenberg, senior research fellow in general practice, ${ }^{1}$ Sandi Powell, endocrinologist, ${ }^{2}$ Kelly Anne \\ Shaw, honorary associate and postdoctoral fellow, ${ }^{1,3}$ Graeme Jones, head of musculoskeletal unit ${ }^{1}$
}

${ }^{1}$ Menzies Research Institute, University of Tasmania, Private Bag 23, Hobart, TAS 7000, Australia

${ }^{2}$ Royal Hobart Hospital, Liverpool St Hobart, Tasmania

${ }^{3}$ ASLaRC Aged Services Unit, Southern Cross University, Coffs Harbour, Queensland, Australia

Correspondence to: T Winzenberg tania.winzenberg@utas.edu.au

Cite this as: BMJ 2011;342:c7254 doi:10.1136/bmi.c7254

\section{ABSTRACT}

Objective To determine the effectiveness of vitamin D supplementation for improving bone mineral density in children and adolescents and if effects vary with factors such as vitamin D dose and vitamin D status.

Design Systematic review and meta-analysis.

Data sources Cochrane Central Register of Controlled Trials, Medline (1966 to present), Embase (1980 to present), CINAHL (1982 to present), AMED (1985 to present), and ISI Web of Science (1945 to present), last updated on 9 August 2009, and hand searching of conference abstracts from key journals.

Study selection Placebo controlled randomised controlled trials of vitamin D supplementation for at least three months in healthy children and adolescents (aged 1 month to <20 years) with bone density outcomes. Two authors independently assessed references for inclusion and study quality and extracted data.

Data synthesis Standardised mean differences of the percentage change from baseline in bone mineral density of the forearm, hip, and lumbar spine and total body bone mineral content in treatment and control groups. Subgroup analyses were carried out by sex, pubertal stage, dose of vitamin $D$, and baseline serum vitamin $D$ concentration. Compliance and allocation concealment were also considered as possible sources of heterogeneity.

Results From 1653 potential references, six studies, totalling 343 participants receiving placebo and 541 receiving vitamin $D$, contributed data to meta-analyses. Vitamin D supplementation had no statistically significant effects on total body bone mineral content or on bone mineral density of the hip or forearm. There was a trend to a small effect on lumbar spine bone mineral density (standardised mean difference $0.15,95 \%$ confidence interval -0.01 to $0.31 ; P=0.07$ ). Effects were similar in studies of participants with high compared with low serum vitamin D levels, although there was a trend towards a larger effect with low vitamin $D$ for total body bone mineral content ( $P=0.09$ for difference). In studies with low serum vitamin $D$, significant effects on total body bone mineral content and lumbar spine bone mineral density were roughly equivalent to a $2.6 \%$ and $1.7 \%$ percentage point greater change from baseline in the supplemented group.
Conclusions It is unlikely that vitamin D supplements are beneficial in children and adolescents with normal vitamin $D$ levels. The planned subgroup analyses by baseline serum vitamin D level suggest that vitamin D supplementation of deficient children and adolescents could result in clinically useful improvements, particularly in lumbar spine bone mineral density and total body bone mineral content, but this requires confirmation.

\section{INTRODUCTION}

Prevention of the common ${ }^{1}$ and costly ${ }^{2}$ public health problem of osteoporosis is of great importance. Low bone mineral density is a major risk factor for osteoporotic fracture. ${ }^{3}$ Peak bone mass and rate of bone loss both impact on bone mineral density in later life ${ }^{4}$ and are equally important risk factors for osteoporotic fracture. ${ }^{5}$ A $10 \%$ increase in peak bone mass is estimated to halve the risk of an osteoporotic fracture in adult life. ${ }^{6}$ Low bone mineral density is also a risk factor for fracture in childhood. ${ }^{7-9}$ Strategies to maximise peak bone mass in children have been identified as a priority area for research. ${ }^{10}$

One such potential strategy is to improve vitamin D levels in children. Vitamin D deficiency is diagnosed by measurement of serum 25-hydroxyvitamin D. ${ }^{11}$ Concentrations above $50 \mathrm{nmol} / \mathrm{L}$ are considered normal, but there is debate about the level of this threshold $^{12}$ because although only lower levels are usually associated with clinical disease such as rickets, the optimal level for bone health may be above 50 $\mathrm{nmol} / \mathrm{L}$. A low vitamin D level in children and adolescents is common enough to be an important public health issue globally across a range of latitudes, including the United Kingdom, ${ }^{13} 14$ other European countries, ${ }^{15-20}$ the United States, ${ }^{21}$ Lebanon, ${ }^{22}$ Australia, ${ }^{2324}$ and New Zealand. ${ }^{112526}$ Overt vitamin $\mathrm{D}$ deficiency leads to rickets, and subclinical vitamin $\mathrm{D}$ deficiency may also affect bone mineralisation, as assessed by dual x ray absorptiometry. ${ }^{15} 1727-29$ Randomised controlled trials of vitamin D supplementation have, however, reported inconsistent results for bone densitometry measures, ${ }^{2730-34}$ and therefore the effectiveness of vitamin D supplementation for improving bone density is unclear. 
With this systematic review we aimed to determine the effectiveness of vitamin D supplementation for improving bone density in healthy children and adolescents, to identify factors modifying any effect, and to determine if any effect persists after supplementation ceases.

\section{METHODS}

The protocol for this review is published elsewhere..$^{35}$ Studies were eligible for inclusion if they were randomised placebo controlled trials of at least three months of vitamin D supplementation, were carried out in healthy children or adolescents aged between 1 month and 20 years, and measured primary outcomes of areal or volumetric bone mineral density, bone mineral content, or quantitative ultrasound measures (broadband ultrasound attenuation, speed of sound, stiffness index).

Although fractures in later life would be the ideal outcome measure, this would require following large numbers of children as participants for decades. No such studies have been done, so we used bone density measures as surrogate outcomes, as is commonly seen in children. ${ }^{36}$ Bone mineral density and content ${ }^{7-9}$ and quantitative ultrasound measures ${ }^{37}$ have all been associated with fracture risk.

\section{Identification of studies}

The electronic literature search was last updated on 9 August 2009. Without language restrictions, we searched the Cochrane Central Register of Controlled Trials, Medline (1966 to present), Embase (1980 to present), CINAHL (1982 to present), AMED (1985 to present), and ISI Web of Science (1945 to present). Web extra appendix 1 gives the search strategy used for Medline, which was adapted as appropriate for other databases.

We hand searched conference abstract issues of key journals for 2007-8: Osteoporosis International, Journal of Bone and Mineral Research, Asia Pacific Journal of Clinical Nutrition, Journal of the American Dietetic Association, Proceedings of the Nutrition Society, Journal of Nutrition. We examined the reference lists and ISI citations of all included studies. Two reviewers assessed potentially relevant articles against the inclusion criteria.

\section{Data collection and analysis}

Two reviewers independently extracted data. We extracted change in bone mineral density and bone mineral content as percentage change from baseline, as well as sex, age, pubertal stage, baseline serum vitamin D levels, ethnicity, type and dose of vitamin $\mathrm{D}$ given, and compliance as possible effect modifiers, along with data on adverse events. No studies reported quantitative ultrasound outcomes. Two reviewers independently assessed each trial's risk of bias, assessing factors such as randomisation, allocation concealment, blinding, completeness of outcome assessment, and selective reporting. Where necessary we contacted authors to obtain information on primary outcome factors.

We converted bone density outcomes to standardised mean differences, calculating a standardised mean difference of the percentage change from baseline in treatment and control groups at each site for which there were sufficient data (bone mineral density for forearm, hip, and lumbar spine and total body bone mineral content). Where clinically useful, we estimated a benefit in units of percentage change since baseline from the standardised mean differences by estimating the pooled standard deviation from the means of the standard deviation of the outcomes in treatment and control groups for each study, and multiplying the standardised mean differences by this. ${ }^{38-40}$

We calculated statistical heterogeneity using a $\chi^{2}$ test on $\mathrm{N}-1$ degrees of freedom, with significance conservatively set at 0.10 . We also assessed inconsistency $\mathrm{I}^{2}$ using the formula $[(\mathrm{Q}-\mathrm{df}) / \mathrm{Q}] \times 100 \%$, where $\mathrm{Q}$ is the $\chi^{2}$ statistic and df is its degrees of freedom, to describe the percentage of the variability in effect estimates due to heterogeneity. We considered a value greater than $50 \%$ as denoting substantial heterogeneity.

Meta-analysis was done according to a fixed effects model. When heterogeneity was considered substantial, we explored its causes by carrying out prespecified subgroup analyses where data were available - that is, subgroups by sex, pubertal stage, dose of vitamin D, baseline vitamin D levels, compliance, and adequacy

\begin{tabular}{|c|c|c|c|c|c|c|c|c|c|}
\hline Study & $\begin{array}{l}\text { Cholecalciferol } \\
\text { dose }\end{array}$ & $\begin{array}{c}\text { Duration } \\
\text { (years) }\end{array}$ & No & Ethnicity & $\begin{array}{l}\text { Pubertal } \\
\text { stage }\end{array}$ & $\begin{array}{c}\text { Female } \\
(\%)\end{array}$ & $\begin{array}{l}\text { Mean (range) age } \\
\text { (years) }\end{array}$ & $\begin{array}{l}\text { Baseline serum } \\
\text { vitamin D level } \\
(\mathrm{nmol} / \mathrm{L})\end{array}$ & Site measured ${ }^{\star}$ \\
\hline Andersen $2008^{52}$ & 400 or $200 \mathrm{IU} /$ day & 1 & 26 & Pakistani & NS & 100 & $12.2 \dagger(10.1-14.7)$ & 7.3-16.9 & Lumbar spine, total body \\
\hline Cheng $2005^{27}$ & 200 IU/day & 2 & 98 & White & Prepubertal & 100 & $11.1(10-12)$ & 49.5 & Hip, lumbar spine, total body \\
\hline Du $2004^{32}$ & 132 IU/day & 2 & 498 & Chinese & Mixed & 100 & $10.1(\mathrm{NS})$ & $17.7-20.6$ & Forearm, total body \\
\hline \multicolumn{10}{|c|}{ El Hajj Fuleihan $2006^{33} 54$ : } \\
\hline Males & $\begin{array}{c}1400 \mathrm{IU} / \text { week } \\
\text { or } 14000 \mathrm{IU} / \text { week }\end{array}$ & 1 & 184 & NS & Mixed & 0 & $13.0(10-17)$ & 40 & $\begin{array}{l}\text { Lumbar spine, hip, } 1 / 3 \text { radius, } \\
\text { total body }\end{array}$ \\
\hline Females & $\begin{array}{c}1400 \mathrm{IU} / \text { week } \\
\text { or } 14000 \mathrm{IU} / \text { week }\end{array}$ & 1 & 179 & NS & Mixed & 100 & $13.2(10-17)$ & 34.9 & $\begin{array}{l}\text { Lumbar spine, hip, } 1 / 3 \text { radius, } \\
\text { total body }\end{array}$ \\
\hline Viljakainen $2006^{34}$ & 400 or 200 IU/day & 1 & 228 & White & & 100 & $11.4(11-12)$ & 47 & Lumbar spine, hip \\
\hline
\end{tabular}


Table 2| Main effects of vitamin D supplementation

\begin{tabular}{lccc} 
Outcome & No of studies & $\begin{array}{c}\text { No of } \\
\text { participants }\end{array}$ & $\begin{array}{c}\text { Standardised mean } \\
\text { difference* }(95 \% \mathrm{Cl})\end{array}$ \\
Hip bone mineral density & 4 & 639 & $0.06(-0.18$ to 0.29$)$ \\
\hline Lumbar spine bone mineral density & 5 & 660 & $0.15(-0.01$ to 0.31)† \\
\hline Total body bone mineral content & 5 & 672 & $0.10(-0.06$ to 0.26) \\
\hline Forearm bone mineral density & 3 & 563 & $0.04(-0.36$ to 0.45$)$ \\
\hline
\end{tabular}

Outcome is percentage change from baseline.

${ }^{*}$ Standardised mean difference of 0.3 regarded as small. ${ }^{59}$

$+\mathrm{P}=0.07$. analysis using random effects models. All analyses were carried out in Review Manager 5 (version 5.0.16).

We performed a priori subgroup analyses by sex, pubertal stage, dose of vitamin $\mathrm{D}$, and baseline vitamin D levels to determine whether the effects of supplementation varied by these factors. As the numbers of studies were small, the cut-offs of $200 \mathrm{IU}$ for vitamin D dose and $35 \mathrm{nmol} / \mathrm{L}$ for baseline vitamin $\mathrm{D}$ concentrations were chosen on the basis of their being sufficient data available at these cut-offs to allow for subgroup analyses. When possible we used intention to treat data in analyses, but if these were not available we used, in order of preference, data from available data or per protocol analyses. Assessment of publication bias was by funnel plot.

Where studies had more than one vitamin D dosage

group, we combined the data from all dosage groups geneity between studies, we proceeded to meta-

of allocation concealment. Data were insufficient to consider ethnicity and sun exposure as possible sources of heterogeneity, as planned in the original protocol. Where there were not clear clinical reasons
or study methodology reasons for substantial hetero-

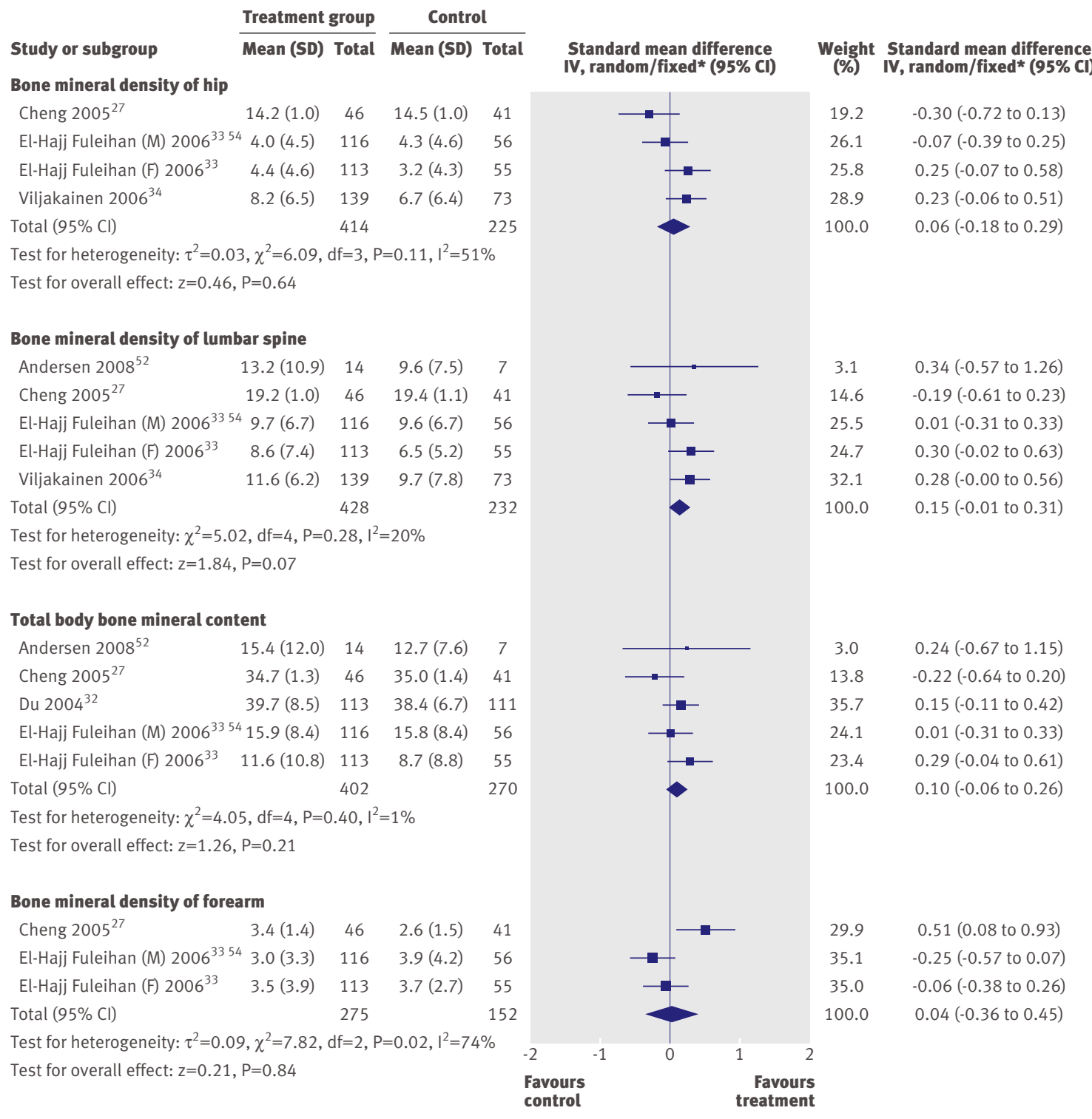

Forest plots of main effects of vitamin D supplementation on bone mineral density of hip, lumbar spine, and forearm, and total body bone mineral content. $M=$ =males; $F=$ females. *Fixed model used for lumbar spine bone mineral density and total body bone mineral content. See web extra for data to two decimal places 
Table 3|Subgroup analyses of effects of vitamin D supplementation by sex

\begin{tabular}{|c|c|c|c|c|c|c|}
\hline \multirow[b]{2}{*}{ Outcome } & \multicolumn{3}{|c|}{ Females } & \multicolumn{3}{|c|}{ Males } \\
\hline & No of studies & $\begin{array}{l}\text { No of } \\
\text { participants }\end{array}$ & $\begin{array}{l}\text { Standardised mean difference* } \\
\qquad(95 \% \mathrm{Cl})\end{array}$ & No of studies & $\begin{array}{l}\text { No of } \\
\text { participants }\end{array}$ & $\begin{array}{l}\text { Standardised mean difference* } \\
\qquad(95 \% \mathrm{Cl})\end{array}$ \\
\hline Hip bone mineral density & 3 & 467 & $0.09(-0.21$ to 0.40$)$ & 1 & 172 & $-0.07(-0.39$ to 0.25$)$ \\
\hline Lumbar spine bone mineral density & 4 & 488 & $0.20(0.01$ to 0.39$) \dagger$ & 1 & 172 & $0.01(-0.31$ to 0.33$)$ \\
\hline Total body bone mineral content & 4 & 500 & $0.13(-0.05$ to 0.31$)$ & 1 & 172 & $0.01(-0.31$ to 0.33$)$ \\
\hline Forearm bone mineral density & 2 & 255 & $0.20(-0.35$ to 0.76$)$ & 1 & 172 & $-0.25(-0.57$ to 0.07$)$ \\
\hline
\end{tabular}

Outcome is percentage change from baseline.

${ }^{*}$ Standardised mean difference of 0.3 regarded as small. ${ }^{59}$

$\dagger$ Statistically significant at $5 \%$ level.

and compared this with placebo. The exception to this was in subgroup analyses by vitamin D dose-for those studies with a dosage group falling into each subgroup we used the data from the individual dosage group for the treatment arms and used the control group mean and standard deviation for each subgroup comparison but reduced the number in the control groups by half for each comparison.

One study was a cluster randomised controlled trial, ${ }^{32}$ with data that did not account for clustering. We used the subsequently published intracluster correlation for total body bone mineral content ${ }^{41}$ in a sensitivity analysis, correcting the sample size for the effect of clustering by the design effect of 1.946 , calculated by $1+(\mathrm{M}-1)$ ICC, where $\mathrm{M}$ is the cluster size and ICC the intracluster correlation (87 and 0.011 , respectively).

\section{RESULTS}

The search identified 1653 references, of which 1599 were excluded at initial independent screening of the title and abstract $(\kappa=0.66)$, with 25 disagreements. The disagreements were resolved by consensus and all 25 were excluded at screening of the abstract. Six references were in German. These were excluded after assessment by a rheumatologist fluent in German in conjunction with one author.

Of the 23 references requiring full text review, 12 references to seven studies were included (see web extra appendix 2). Studies were excluded for several reasons: not randomised controlled trials (four studies), ${ }^{42-45}$ participants not within age range 1 month to 20 years (three studies), ${ }^{46-48}$ bone density outcomes not measured (two studies), ${ }^{495}$ no vitamin D intervention (one study), ${ }^{51}$ and not placebo controlled trial (one study). ${ }^{16}$ One study was excluded for not reporting a variance measure..$^{30}$ This study was small $(n=60)$ and reported no effect of supplementation for bone mineral content at the distal one third of the radius.

The meta-analysis used data from six studies, with 343 participants receiving placebo and 541 receiving vitamin D (table 1). ${ }^{2731-3452}$ The full review provides more detailed information on these studies. ${ }^{54}$ Participants were aged from 8 to 17 years. Bone density was measured by dual $x$ ray absorptiometry in all studies except one in which volumetric bone mineral density was measured using peripheral quantitative computed tomography at the distal radius. ${ }^{27}$ No studies measured quantitative ultrasound outcomes. All studies administered vitamin $\mathrm{D}_{3}$ (cholecalciferol), with the dose ranging from 132 IU daily ${ }^{32}$ to 14000 IU per week $^{3133}$ over one 1133452 $^{31}$ two ${ }^{2732}$ years. One study provided follow-up data for three years after supplementation. ${ }^{32}$ Two studies included cointerventions, one of milk, providing an average of $245 \mathrm{mg} /$ day of calcium to both control and supplement groups, ${ }^{32}$ and one of $1000 \mathrm{mg} /$ day of calcium carbonate in both vitamin D and control groups. ${ }^{27}$ Mean baseline serum vitamin D levels ranged from 17.7 to $49.5 \mathrm{nmol} / \mathrm{L}$. Results from available data analysis were extracted for all studies except one, ${ }^{32}$ which reported per protocol analysis, excluding 33 participants with poor compliance.

\section{Risk of bias}

One study had clearly documented and adequate sequence generation, allocation concealment, blinding, and reasons for withdrawals. ${ }^{27}$ Two other studies described adequate sequence generation and allocation concealment, ${ }^{313354}$ and in the remaining three studies these were unclear. ${ }^{323452}$ All studies were stated to be double blind, although the blinding process was not fully described. The risk of bias from this was, however, assessed as very low as it is unlikely that bone density outcomes could be influenced by lack of blinding. No study reported imputing for missing data in the analysis, but loss to follow-up was for the most part either evenly distributed across groups ${ }^{31335254}$ or reasons for withdrawal were stated and unlikely to be related to the true outcome. ${ }^{2734}$ Incomplete outcome data posed a risk of bias in one study in which forearm bone mineral density was measured but not reported. ${ }^{32}$

Although the number of studies was small, funnel plots suggested that publication bias was not present (data not shown, see full review for details ${ }^{53}$ ).

\section{Effects of interventions}

Table 2 gives the main effects of vitamin D supplementation at different sites (see also figure). Overall, vitamin D supplementation did not have statistically significant effects on percentage change in total body bone mineral content or bone mineral density of the hip or forearm. There was a trend to a small effect on lumbar spine bone mineral density (standardised mean difference $0.15,95 \%$ confidence interval -0.01 to 0.31 , $\mathrm{P}=0.07)$. The results for percentage change were statistically heterogeneous for bone mineral density of the 
Table 4 | Subgroup analyses of effects of vitamin D supplementation by baseline serum vitamin D level

\begin{tabular}{|c|c|c|c|c|c|c|}
\hline \multirow[b]{2}{*}{ Outcome } & \multicolumn{3}{|c|}{ Low baseline vitamin D level ( $(35 \mathrm{nmol} / \mathrm{L})$} & \multicolumn{3}{|c|}{ High baseline vitamin D level ( $\geq 35 \mathrm{nmol} / \mathrm{L})$} \\
\hline & No of studies & $\begin{array}{l}\text { No of } \\
\text { participants }\end{array}$ & $\begin{array}{l}\text { Standardised mean difference* } \\
\qquad(95 \% \mathrm{Cl})\end{array}$ & No of studies & $\begin{array}{l}\text { No of } \\
\text { participants }\end{array}$ & $\begin{array}{l}\text { Standardised mean difference* } \\
\qquad(95 \% \mathrm{Cl})\end{array}$ \\
\hline Hip bone mineral density & 1 & 168 & $0.25(-0.07$ to 0.58$)$ & 3 & 471 & $-0.02(-0.31$ to 0.28$)$ \\
\hline Lumbar spine bone mineral density & 2 & 189 & $0.31(0.00$ to 0.61$) \dagger$ & 3 & 471 & $0.09(-0.10$ to 0.28$)$ \\
\hline Total body bone mineral content & 3 & 413 & $0.21(0.01$ to 0.41$) \ddagger$ & 2 & 259 & $-0.07(-0.33$ to 0.18$) \S$ \\
\hline Forearm bone mineral density & 1 & 168 & $-0.06(-0.38$ to 0.26$)$ & 2 & 259 & $0.12(-0.62$ to 0.85$)$ \\
\hline
\end{tabular}

Outcome is percentage change from baseline.

* Standardised mean difference of 0.3 regarded as small. ${ }^{59}$

$+\mathrm{P}=0.05$.

$\ddagger$ Statistically significant at $5 \%$ level.

$\S \mathrm{P}=0.09$ for difference.

hip $\left(\chi^{2}=6.09, \mathrm{df}=3, \mathrm{P}=0.11, \mathrm{I}^{2}=51 \%\right)$ and forearm $\left(\chi^{2}=7.82, \mathrm{df}=2, \mathrm{P}=0.02, \mathrm{I}^{2}=74 \%\right)$ but not at other sites. The use of data on total body bone mineral content corrected for cluster effects ${ }^{32}{ }^{41}$ did not materially affect the result (total body bone mineral content standardised mean difference $0.09,-0.08$ to 0.26 ).

\section{Heterogeneity}

Sex, baseline serum vitamin D level, and adequacy of allocation concealment did not explain heterogeneity seen between studies for analyses of hip and forearm bone mineral density. One study comprised males only. Heterogeneity was still significant in studies in females (hip: $\chi^{2}=4.94, \mathrm{df}=2, \mathrm{P}=0.08, \mathrm{I}^{2}=60 \%$; forearm: $\left.\chi^{2}=4.32, \mathrm{df}=1, \mathrm{P}=0.04, \mathrm{I}^{2}=60 \%\right)$. One study with outcomes for hip and forearm bone mineral density comprised participants with a mean baseline serum vitamin D concentration less than $35 \mathrm{nmol} / \mathrm{L}$. Significant heterogeneity remained in those studies with participants who had a baseline serum vitamin $\mathrm{D}$ concentration above this level (hip: $\chi^{2}=4.54, \mathrm{df}=2, \mathrm{P}=0.10, \mathrm{I}^{2}=56 \%$; forearm: $\chi^{2}=7.66, \mathrm{df}=1, \mathrm{P}=0.006, \mathrm{I}^{2}=87 \%$ ). In subgroup analysis by allocation concealment (adequate compared with inadequate or unclear) heterogeneity remained in the adequate allocation concealment subgroup for hip bone mineral density $\left(\chi^{2}=4.47, \mathrm{df}=2\right.$, $\left.\mathrm{P}=0.11, \mathrm{I}^{2}=55 \%\right)$. No studies had inadequate or unclear allocation concealment for forearm bone mineral density, so subgroup analysis could not be done.

Classification of studies into subgroups by compliance and by pubertal status of participants in the study as a whole resulted in identical subgroups. Only one study was in purely prepubertal children, ${ }^{27}$ and this was the only study with low compliance. All other studies were in children and adolescents of mixed pubertal status with high compliance. In the mixed pubertal stage and high compliance subgroup, heterogeneity was not significant at either the hip or the forearm $\left(\chi^{2}=2.55, \mathrm{df}=2, \mathrm{P}=0.28, \mathrm{I}^{2}=22 \%\right.$; and $\chi^{2}=0.64$, $\mathrm{df}=1, \mathrm{P}=0.42, \mathrm{I}^{2}=0 \%$.

\section{Subgroup analyses for differences in effects}

The effects of supplementation at all sites were similar regardless of vitamin $\mathrm{D}$ dose given $>200$ IU daily $v$ $\leq 200$ IU daily; data not shown, see full Cochrane review for details ${ }^{54}$ ) and sex (table 3). In females but not in males, however, the effect on lumbar spine bone mineral density was statistically significant. There was a trend for larger effect in the low serum vitamin D subgroup of studies for total body bone mineral content $(\mathrm{P}=0.09$ for subgroup difference), but effects were similar between low and high serum vitamin $\mathrm{D}$ groups at other sites (table 4). In the low serum vitamin D studies, however, the effect for total body bone mineral content was significant $(\mathrm{P}=0.04)$, and the result for lumbar spine bone mineral density bordered on significance $(\mathrm{P}=0.05)$.

Vitamin D supplementation had a greater effect for forearm bone mineral density in studies in prepubertal and low compliance children (table 5) but the direction of this effect was the opposite of that observed at other sites. We also compared effects in prepubertal (Tanner stage 1 or 2) and postpubertal (Tanner stage 3 and 4) young people derived from within individual studies. These did not show any significant differences in effects between groups at any site (table 6).

\section{Sensitivity analyses}

Correcting for intracluster correlation in one study did not materially affect the results for total body bone mineral content (data not shown). ${ }^{32}$ In light of the findings about the explanatory effect for heterogeneity in Cheng 2005, ${ }^{27}$ subgroup analyses were repeated by sex, baseline serum vitamin D level, dose of cholecalciferol, and adequacy of allocation concealment, omitting this study where there was heterogeneity within any subgroup. This was possible only for hip bone mineral density owing to the number of studies involved. This reduced heterogeneity to non-significant levels. An effect on hip bone mineral density in females was found (standardised mean difference $0.24,95 \%$ confidence interval 0.03 to $0.45, \mathrm{P}=0.03$ ), which was not seen when Cheng 2005 was included, but the effect size was still similar in both sexes. Results of analyses for hip bone mineral density by serum vitamin D level, dose of cholecalciferol, and allocation concealment were similar to those of the analyses including Cheng 2005 (data not shown).

\section{Benefits after supplementation ceases}

One study ${ }^{3255}$ provided follow-up data after supplementation ceased. Total body bone mineral content 
Table 5 |Subgroup analyses of effects of vitamin D supplementation by pubertal status and compliance

\begin{tabular}{|c|c|c|c|c|c|c|}
\hline \multirow[b]{2}{*}{ Outcome } & \multicolumn{3}{|c|}{ Prepubertal and low compliance } & \multicolumn{3}{|c|}{ Mixed pubertal and high compliance } \\
\hline & No of studies & $\begin{array}{c}\text { No of } \\
\text { participants }\end{array}$ & $\begin{array}{l}\text { Standardised mean difference* } \\
\qquad(95 \% \mathrm{Cl})\end{array}$ & No of studies & $\begin{array}{c}\text { No of } \\
\text { participants }\end{array}$ & $\begin{array}{l}\text { Standardised mean difference } \\
\qquad(95 \% \mathrm{Cl})\end{array}$ \\
\hline Hip bone mineral density & 1 & 87 & $-0.30(-0.72$ to 0.13$)$ & 3 & 552 & $0.14(-0.3$ to 0.32$)$ \\
\hline Lumbar spine bone mineral density & 1 & 87 & $-0.19(-0.61$ to 0.23$)$ & 4 & 573 & $0.21(0.04$ to 0.38$) \dagger \ddagger$ \\
\hline Total body bone mineral content & 1 & 87 & $-0.22(-0.64$ to 0.20$)$ & 4 & 585 & $0.15(-0.02$ to 0.32$)$ \\
\hline Forearm bone mineral density & 1 & 87 & $0.51(0.08$ to 0.93$) \dagger$ & 2 & 340 & $-0.16(-0.38$ to 0.07$)$ \\
\hline
\end{tabular}

Outcome is percentage change from baseline.

* Standardised mean difference of 0.3 regarded as small. ${ }^{59}$

$\dagger$ Statistically significant at $5 \%$ level.

$\ddagger \mathrm{P}=0.09$ for difference.

between the group receiving calcium supplemented milk and the group receiving calcium and vitamin D supplemented milk did not differ significantly three years after supplementation ceased (percentage change since baseline 71.9 (SD 1.5) and 70.8 (SD 1.5), respectively).

\section{Adverse events}

Reporting of adverse events was limited but suggested that vitamin D supplementation is well tolerated. No children developed hypercalcaemia in one study. ${ }^{52} \mathrm{In}$ another study, four children dropped out through disease onset described as unrelated to the trial, but gave no further details. ${ }^{27}$ In another, one child withdrew owing to skin allergy, but the intervention arm to which the child belonged and potential relationship to vitamin $\mathrm{D}$ was not reported. ${ }^{32}$ One study reported that treatment was well tolerated, ${ }^{33}$ with two participants in the placebo group having increased serum calcium levels at the end of one year, and one girl who received cholecalciferol 1400 IU/week developing post-streptococcal glomerulonephritis. In boys, three participants in the placebo group and one in each vitamin dose group had increased serum calcium levels at one year. ${ }^{3354}$ The final study reported that 16 children dropped out for reasons not related to the study protocol, but gave no further details. ${ }^{34}$

\section{DISCUSSION}

This systematic review indicates that targeting children and adolescents with low serum vitamin D concentrations could result in clinically important improvements in bone density but that vitamin D supplementation in healthy children and adolescents generally to improve bone density is not justified.

\section{Clinical and policy implications}

Although it is difficult to extrapolate bone density outcomes in childhood to reduction in risk of fracture in adulthood, our results suggest that it is plausible that vitamin $\mathrm{D}$ supplementation in deficient children and adolescents can deliver clinically significant improvements in bone health. For example, the magnitude of the standardised mean differences of effects in children and adolescents with low baseline serum vitamin D concentrations were 0.21 for total body bone mineral content, 0.31 for lumbar spine bone mineral density, and 0.25 for hip bone mineral density, all of which were at least 0.2 standardised mean differences higher than in children and adolescents with high baseline vitamin D levels. This standardised mean difference is about equivalent to a $2.6 \%$ point greater change in total body bone mineral content from baseline in the vitamin D supplemented group than in the control group. Equivalent estimates were 1\% for hip bone mineral density and 1.7\% for lumbar spine bone mineral density. Effects at the forearm were neither statistically nor clinically significant. The available studies did not allow us to ascertain whether the effects of supplementation accumulate while supplementation continues or if the effect plateaus over time. However, if a 10\% increase in peak bone mass can, as postulated, reduce the risk of an osteoporotic fracture in adult life by $50 \%,{ }^{6}$ an effect on fracture risk in later life of both clinical and public health significance is achievable, particularly if effects do accumulate. Children with wrist and forearm fractures have a bone mineral density up to $8 \%$ lower than children without such fractures. $^{7-9}$ We estimate that a $5 \%$ increase in total body bone mineral density and bone mineral density of the hip or lumbar spine could decrease the relative risk of fracture in childhood by about $17 \%$ and $9 \%$, respectively. ${ }^{9}$ Thus, vitamin D supplementation has the potential to have a substantial effect on adult fracture rates and an effect in childhood.

In light of these data, the approach to addressing vitamin D deficiency in children and adolescents warrants further consideration. Possible choices include fortification of food or direct supplementation at either population or individual level. In trials of increasing vitamin $\mathrm{D}$ intake in children, whether through fortification of food or supplements, it is possible to achieve increases in serum vitamin D levels, but the doses of cholecalciferol required to correct deficiency and reach post-intervention vitamin $\mathrm{D}$ concentrations above $50 \mathrm{nmol} / \mathrm{L}$ are in excess of $400 \mathrm{IU} /$ day. ${ }^{56}$ Thus, while food fortification may offer some protection against vitamin $\mathrm{D}$ deficiency in children, ${ }^{57}$ it is unlikely a sufficient dose could be delivered to achieve adequate serum levels in children with deficiency. Unfortunately, the alternative of screening for vitamin $\mathrm{D}$ deficiency and then correcting it is more costly and relatively invasive. The cost effectiveness and acceptability of screening remains to be established, 
Table 6 | Subgroup analyses of effects of vitamin D supplementation by pubertal status

\begin{tabular}{|c|c|c|c|c|c|c|}
\hline \multirow[b]{2}{*}{ Outcome } & \multicolumn{3}{|c|}{ Prepubertal (Tanner stage 1 or 2 ) } & \multicolumn{3}{|c|}{ Postpubertal (Tanner stage 3 or 4 ) } \\
\hline & No of studies* & $\begin{array}{c}\text { No of } \\
\text { participants }\end{array}$ & $\begin{array}{c}\text { Standardised mean difference } † \\
(95 \% \mathrm{Cl})\end{array}$ & No of studies* & $\begin{array}{c}\text { No of } \\
\text { participants }\end{array}$ & $\begin{array}{c}\text { Standardised mean difference } † \\
(95 \% \mathrm{Cl})\end{array}$ \\
\hline Hip bone mineral density & 4 & 335 & $0.00(-0.36$ to 0.37$)$ & 3 & 304 & $0.17(-0.07$ to 0.40$)$ \\
\hline Lumbar spine bone mineral density & 4 & 335 & $0.01(-0.22$ to 0.24$)$ & 3 & 304 & $0.16(-0.07$ to 0.40$)$ \\
\hline Total body bone mineral content & 4 & 318 & $-0.01(-0.24$ to 0.22$)$ & 3 & 325 & $0.18(-0.05$ to 0.40$)$ \\
\hline Forearm bone mineral density & 3 & 213 & $0.13(-0.45$ to 0.72$)$ & 2 & 214 & $0.06(-0.23$ to 0.34$)$ \\
\hline
\end{tabular}

Outcome is percentage change from baseline.

*Where total number of studies compared exceeds six, studies contribute data to more than one subgroup.

†Standardised mean difference of 0.3 is regarded as small. ${ }^{59}$

including carrying out further randomised controlled trials to assess the benefits of doing so for bone health.

\section{Potential effect modifiers}

Besides baseline serum vitamin D levels, other potential modifiers of the effect of vitamin D supplementation include sex, pubertal status, and compliance, although the paucity of evidence available to examine potential effect modification means that definitive conclusions cannot be drawn. Based on the current evidence, it may be that vitamin $\mathrm{D}$ deficient females are the subgroup likely to have the greatest response to supplementation, but the paucity of data in males means that this is not certain. The average baseline vitamin $\mathrm{D}$ concentration in males was $5 \mathrm{nmol} / \mathrm{L}$ lower than that of females, which could contribute to any difference. Unfortunately, studies of subgroups of prepubertal compared with mixed pubertal stages and those of low and high compliance were identical, making it difficult to separate effects of these factors. However, when participants were divided within studies into prepubertal (Tanner stage 1 or 2) and postpubertal (Tanner stage 3 or 4 ) groups, the effects between subgroups did not differ, suggesting that compliance, rather than pubertal stage, is more likely to be an effect modifier. The direction of effect was inconsistent at the forearm compared with other sites in the analysis by pubertal status and compliance subgroups. For forearm bone mineral density the overall effect was 0.67 , favouring the control group in the prepubertal and low compliance study $^{27}$ but the direction of effects favoured vitamin D supplementation at the hip, lumbar spine, and total body bone mineral content. This could reflect genuine differences in the response of cortical bone (predominates at distal third of radius) compared with trabecular bone (predominates at lumbar spine, femoral neck, and total body bone mineral content). However, it is unclear why the control group would show an effect at any site. The available data do not allow this to be adequately addressed, and caution is needed in interpreting this analysis.

\section{Limitations of the review}

The number of studies contributing substantial data to the meta-analysis was small. ${ }^{271-34}$ We therefore could not fully assess the effects of important clinical factors that might influence outcomes of supplementation. For example, we could not examine the interplay between compliance, dose of cholecalciferol, and baseline vitamin D levels. This interplay might have been able to explain the lack of any difference in effect by dose should the data have allowed this to be examined. We could not adequately investigate sex differences, and data were too few to assess effects after supplementation ceased. The cut-off of $35 \mathrm{nmol} / \mathrm{L}$ to define low serum vitamin $\mathrm{D}$ concentration in subgroup analyses was arbitrarily chosen based on the distribution of data, so as to enable subgroup analyses. The main study contributing data to the subgroup with low baseline vitamin D level, however, included around $20 \%$ of participants with concentrations above $50 \mathrm{nmol} / \mathrm{L}$. The effect sizes we found may therefore underestimate the benefits of supplementation in deficient children and adolescents. Further randomised controlled trials are needed to determine the maximum benefit obtainable by supplementing vitamin $\mathrm{D}$ deficient children and adolescents, whether benefits accrue with increasing duration of supplementation, below what serum vitamin $\mathrm{D}$ level benefits of supplementation can be seen, and whether benefits persist after supplementation ceases. The effects in children and adolescents overall at any site were not statistically significant, and the observed effect sizes were also consistently small and unlikely to be clinically significant, with standardised mean differences ranging from 0.04 to 0.15 (table 2). Although it would take a large study with a strongly positive result to cause a noticeable increase in effect size, the limited number of studies and relatively low overall numbers of participants could reduce the robustness of our findings, and as results from further studies become available it is important that this analysis is updated. It has been suggested that areal bone mineral density only partly corrects for bone size and that adjustment of bone mineral content for bone area, weight, and height is desirable. ${ }^{58}$ Only one study, however, reported any such data. ${ }^{34}$ The study's results using this outcome were consistent with the meta-analysis results, with no statistically significant effect with vitamin D supplements at either the hip or lumbar spine. Only surrogate outcomes could be used in this review because of the current lack of data on fracture outcome. In future studies consideration should therefore be given to including childhood fractures as an outcome. The use of fractures in older adult life as an outcome will, however, remain problematic owing to the lengthy follow-up periods that would be required. 


\section{WHAT IS ALREADY KNOWN ON THIS TOPIC}

\section{Vitamin D deficiency is common}

Subclinical vitamin D deficiency in children seems detrimental to bone health

The results of randomised controlled trials of vitamin D supplements in children and adolescents are inconsistent

\section{WHAT THIS STUDY ADDS}

Vitamin D supplements are unlikely to be beneficial in children and adolescents with normal vitamin D levels

Vitamin D supplementation of deficient children and adolescents could result in clinically useful improvements in bone density but this requires confirmation in further studies targeting deficient children and adolescents

\section{Conclusion}

In conclusion, it is unlikely that vitamin D supplements are beneficial in children and adolescents with normal vitamin D levels. Our planned subgroup analyses by baseline serum vitamin D level suggest that vitamin D supplementation of deficient children and adolescents could result in clinically useful improvements, particularly in bone mineral density of the lumbar spine and total body bone mineral content, but this requires confirmation.

This paper is based on a Cochrane review published in the Cochrane Library 2010, Issue 10 (see www.thecochranelibrary.com for information). Cochrane reviews are regularly updated as new evidence emerges and in response to feedback, and the Cochrane Library should be consulted for the most recent version of the review.

Contributors: TW wrote the review protocol; carried out the data extraction, quality assessment of articles, and analyses; and wrote the discussion of review results with the input of other authors. She is the guarantor. KAS reviewed articles to decide on inclusion, had input into writing of the protocol, and was involved in the writing of discussion of review results. SP had input into writing of the protocol, reviewed initial search for articles to decide on inclusion, carried out data extraction and quality assessment of articles, and was involved in the writing of discussion of review results. She also has content knowledge in the field of vitamin D. GJ is the content expert in paediatric bone health for the review. He provided input into design of the protocol and assisted with the analysis and with writing the discussion of review results. All authors had full access to all of the data (including statistical reports and tables) in the study and can take responsibility for the integrity of the data and the accuracy of the data analysis.

Funding: TW received a National Health and Medical Research Counci training fellowship and G) receives a National Health and Medical Research Council practitioner fellowship. The funding body had no input into any aspect of this study.

Competing interests: All authors have completed the Unified Competing Interest form at www.icmje.org/coi_disclosure.pdf (available on request from the corresponding author) and declare that TW and GJ received fellowships from the National Health and Medical Research Council while undertaking this work. TW, SP, KAS, and GJ have no relationships with any company that might have an interest in the submitted work in the previous 3 years; their spouses, partners, or children have no financial relationships that may be relevant to the submitted work; and have no non-financial interests that may be relevant to the submitted work.

Ethical approval: Not required.

Data sharing: No additional data available.

1 Johnell O, Kanis JA. An estimate of the worldwide prevalence and disability associated with osteoporotic fractures. Osteoporos Int 2006;17:1726-33.

2 Burge R, Dawson-Hughes B, Solomon DH, Wong JB, King A, Tosteson A. Incidence and economic burden of osteoporosis-related fractures in the United States, 2005-2025. J Bone Miner Res 2007;22:465-75.
3 Marshall D, Johnell O, Wedel H. Meta-analysis of how well measures of bone mineral density predict occurrence of osteoporotic fractures. BMJ 1996;312:1254-9.

4 Hansen MA, Overgaard K, Riis BJ, Christiansen C. Role of peak bone mass and bone loss in postmenopausal osteoporosis: 12 year study. BMJ 1991;303:961-4.

5 Riis BJ, Hansen MA, Jensen AM, Overgaard K, Christiansen C. Low bone mass and fast rate of bone loss at menopause: equal risk factors for future fracture: a 15-year follow-up study. Bone 1996;19:9-12.

6 Cummings SR, Black DM, Nevitt MC, Browner W, Cauley J, Ensrud K, et al. Bone density at various sites for prediction of hip fractures. The Study of Osteoporotic Fractures Research Group. Lancet 1993;341:72-5.

7 Goulding A, Cannan R, Williams SM, Gold EJ, Taylor RW, Lewis-Barned NJ. Bone mineral density in girls with forearm fractures. J Bone Miner Res 1998;13:143-8.

8 Goulding A, Jones IE, Taylor RW, Williams SM, Manning PJ. Bone mineral density and body composition in boys with distal forearm fractures: a dual-energy x-ray absorptiometry study. J Pediatr 2001;139:509-15.

9 Ma $\mathrm{D}$, Jones $\mathrm{G}$. The association between bone mineral density, metacarpal morphometry, and upper limb fractures in children: a population-based case-control study. J Clin Endocrinol Metab 2003;88:1486-91.

10 Osteoporosis prevention, diagnosis and therapy. NIH Consensus Statement 2000;17:1-45.

11 Munns C, Zacharin MR, Rodda CP, Batch JA, Morley R, Cranswick NE, et al. Prevention and treatment of infant and childhood vitamin $D$ deficiency in Australia and New Zealand: a consensus statement. Med J Aust 2006;185:268-72.

12 Holick MF. Vitamin D deficiency. N Engl J Med 2007;357:266-81.

13 Das G, Crocombe S, McGrath M, Berry JL, Mughal MZ. Hypovitaminosis D among healthy adolescent girls attending an inner city school. Arch Dis Child 2006;91:569-72.

14 Sharma S, Khan N, Khadri A, Julies P, Gnanasambandam S, Saroey S, et al. Vitamin $D$ in pregnancy - time for action: a paediatric audit. BJOG 2009;116:1678-82.

15 Zamora SA, Rizzoli R, Belli DC, Slosman DO, Bonjour JP. Vitamin D supplementation during infancy is associated with higher bone mineral mass in prepubertal girls. J Clin Endocrinol Metab 1999;84:4541-4.

16 Guillemant J, Le HT, Maria A, Allemandou A, Peres G, Guillemant S. Wintertime vitamin $D$ deficiency in male adolescents: effect on parathyroid function and response to vitamin D3 supplements. Osteoporos Int 2001;12:875-9.

17 Outila TA, Karkkainen MU, Lamberg-Allardt CI. Vitamin D status affects serum parathyroid hormone concentrations during winter in female adolescents: associations with forearm bone mineral density. Am J Clin Nutr 2001;74:206-10.

18 Lehtonen-Veromaa MK, Mottonen T, Nuotio IO, Irjala KM, Leino AE, Viikari JS. Vitamin D and attainment of peak bone mass among peripubertal Finnish girls: a 3-y prospective study. Am J Clin Nutr 2002;76:1446-53.

19 Cheng S, Tylavsky F, Kroger H, Karkkainen M, Lyytikainen A, Koistinen A, et al. Association of low 25 -hydroxyvitamin D concentrations with elevated parathyroid hormone concentrations and low cortical bone density in early pubertal and prepuberta Finnish girls. Am J Clin Nutr 2003;78:485-92.

20 Tylavsky FA, Cheng S, Lyytikainen A, Viljakainen H, Lamberg-Allardt C. Strategies to improve vitamin D status in northern European children: exploring the merits of vitamin D fortification and supplementation. Nutr 2006;136:1130-4.

21 Looker AC, Dawson-Hughes B, Calvo MS, Gunter EW, Sahyoun NR. Serum 25-hydroxyvitamin D status of adolescents and adults in two seasonal subpopulations from NHANES III. Bone 2002;30:771-7.

22 El-Hajj Fuleihan G, Nabulsi M, Choucair M, Salamoun M, Hajj Shahine C, Kizirian A, et al. Hypovitaminosis D in healthy schoolchildren. Pediatrics 2001;107:E53.

23 Jones G, Blizzard C, Riley MD, Parameswaran V, Greenaway TM, Dwyer T. Vitamin D levels in prepubertal children in southern Tasmania: prevalence and determinants. Eur J Clin Nutr 1999;53:824-9.

24 Jones G, Dwyer T, Hynes KL, Parameswaran V, Greenaway TM. Vitamin D insufficiency in adolescent males in southern Tasmania: prevalence, determinants, and relationship to bone turnover markers. Osteoporos Int 2005;16:636-41.

25 Rockell JE, Green TJ, Skeaff CM, Whiting SJ, Taylor RW, Williams SM, et al. Season and ethnicity are determinants of serum 25 hydroxyvitamin D concentrations in New Zealand children aged 5-14 y. J Nutr 2005;135:2602-8.

26 Rockell JE, Skeaff CM, Williams SM, Green TJ. Serum 25hydroxyvitamin D concentrations of New Zealanders aged 15 years and older. Osteoporos Int 2006;17:1382-9. 
27 Cheng S, Lyytikainen A, Kroger H, Lamberg-Allardt C, Alen M, Koistinen A, et al. Effects of calcium, dairy product, and vitamin D supplementation on bone mass accrual and body composition in 10 12-y-old girls: a 2-y randomized trial. Am J Clin Nutr 2005;82:1115-26, quiz 1147-8.

28 Jones G, Dwyer T. Bone mass in prepubertal children: gender differences and the role of physical activity and sunlight exposure. Clin Endocrinol Metab 1998;83:4274-9.

29 Lehtonen-Veromaa M, Mottonen T, Irjala K, Karkkainen M, Lamberg-Allardt C, Hakola P, et al. Vitamin D intake is low and hypovitaminosis D common in healthy 9- to 15-year-old Finnish girls. Eur J Clin Nutr 1999;53:746-51.

30 Ala-Houhala M, Koskinen T, Koskinen M, Visakorpi JK. Double blind study on the need for vitamin D supplementation in prepubertal children. Acta Paediatr Scand 1988;77:89-93.

31 El-Hajj Fuleihan G, Nabulsi M, Tamim H, Maalouf J, Salamoun M, Choucair M, et al. Impact of vitamin D supplementation on musculoskeletal parameters in adolescents: a randomised trial. J Bone Miner Res 2004;19(suppl 1):S13.

32 Du X, Zhu K, Trube A, Zhang Q, Ma G, Hu X, et al. School-milk intervention trial enhances growth and bone mineral accretion in Chinese girls aged 10-12 years in Beijing. Br J Nutr 2004;92:159-68.

33 El-Hajj Fuleihan G, Nabulsi M, Tamim H, Maalouf J, Salamoun M, Khalife $\mathrm{H}$, et al. Effect of vitamin D replacement on musculoskeletal parameters in school children: a randomized controlled trial. J Clin Endocrinol Metab 2006;91:405-12.

34 Viljakainen HT, Natri AM, Karkkainen M, Huttunen MM, Palssa A, Jakobsen J, et al. A positive dose-response effect of vitamin D supplementation on site-specific bone mineral augmentation in adolescent girls: a double-blinded randomized placebo-controlled 1-year intervention. / Bone Miner Res 2006;21:836-44.

35 Winzenberg TM, Powell S, Shaw KA, Jones G. Vitamin D supplementation for improving bone mineral density in children. (Protocol) Cochrane Database Syst Rev 2008;1:CD006944.

36 Gilsanz V. Bone density in children: a review of the available techniques and indications. Eur J Radiol 1998;26:177-82.

37 Marin F, Gonzalez-Macias J, Diez-Perez A, Palma S, Delgado-Rodriguez M. Relationship between bone quantitative ultrasound and fractures: a meta-analysis. J Bone Miner Res 2006;21:1126-35.

38 Alderson P, Green S. Additional module 1: meta-analysis of continuous data. Cochrane Collaboration, 2002.

39 Winzenberg T, Shaw K, Fryer J, Jones G. Effects of calcium supplementation on bone density in healthy children: meta-analysis of randomised controlled trials. BMJ 2006;333:775.

40 Winzenberg TM, Shaw K, Fryer J, Jones G. Calcium supplementation for improving bone mineral density in children. Cochrane Database Syst Rev 2006;2:CD005119.

41 Du X, Zhu K, Trube A, Fraser DR, Greenfield AH, Zhang Q, et al. Effects of school-milk intervention on growth and bone mineral accretion in Chinese girls aged 10-12 years: accounting for cluster randomisation. BrJ Nutr 2005;94:1038-9.

42 Calvo MS. Dietary considerations to prevent loss of bone and renal function. Nutrition 2000;16:564-6.

43 Clutterbuck J. The prevention and treatment of osteoporosis-part (i) of (ii). Int J Alternat Complement Med 1995;13:19-22.
44 Compston J. Vitamin D helps stem bone loss. Nurs Times 1998;94:47.

45 Flynn A. The role of dietary calcium in bone health. Proc Nutr Soc 2003;62:851-8

46 Fehily AM, Coles RJ, Evans WD, Elwood PC. Factors affecting bone density in young adults. Am J Clin Nutr 1992;56:579-86.

47 Matsumoto T, Kubodera N. ED-71, a new active vitamin D3, increases bone mineral density regardless of serum 25(OH)D levels in osteoporotic subjects. J Steroid Biochem Mol Biol 2007;103:584-6.

48 Venkataraman PS, Luhar H, Neylan MJ. Bone mineral metabolism in full-term infants fed human milk, cow milk-based, and soy-based formulas. Am J Dis Child 1992;146:1302-5.

49 Duhamel JF, Zeghoud F, Sempe M, Boudailliez B, Odievre M, Laurans $\mathrm{M}$, et al. [Prevention of vitamin D deficiency in adolescents and pre-adolescents. An interventional multicenter study on the biological effect of repeated doses of 100,000 IU of vitamin D3.] Arch Pediatr 2000;7:148-53.

50 Ho ML, Yen HC, Tsang RC. Randomized study of sunshine exposure and serum 25-OHD in breast-fed infants in Beijing, China. J Pediatr 1985;107:928-31.

51 Feliciano ES, Ho ML, Specker BL, Falciglia G, Shui QM, Yin TA, et al. Seasonal and geographical variations in the growth rate of infants in China receiving increasing dosages of vitamin D supplements. J Trop Pediatr 1994;40:162-5.

52 Andersen R, Molgaard C, Skovgaard LT, Brot C, Cashman KD, Jakobsen J, et al. Effect of vitamin D supplementation on bone and vitamin D status among Pakistani immigrants in Denmark: a randomised double-blinded placebo-controlled intervention study. Br J Nutr 2008;100:197-207.

53 Winzenberg TM, Powell S, Shaw KA, Jones G. Vitamin D supplementation for improving bone mineral density in children. Cochrane Database Syst Rev 2010;10:CD006944.

54 El-Hajj Fuleihan G, Vieth R. Vitamin D insufficiency and musculoskeletal health in children and adolescents. In: Burckhardt P, Heaney R, Dawson-Hughes B, eds. Nutritional aspects of osteoporosis 2006, proceedings of the international symposium on nutritional aspects of osteoporosis, 4-6 May 2006, Lausanne, Switzerland. Elsevier, 2007.

55 Zhu K, Zhang Q, Foo LH, Trube A, Ma G, Hu X, et al. Growth, bone mass, and vitamin $D$ status of Chinese adolescent girls 3 y after withdrawal of milk supplementation. Am / Clin Nutr 2006;83:714-21.

56 Cranney A, Horsley T, O’Donnell S, Weiler H, Puil L, Ooi D, et al. Effectiveness and safety of vitamin D in relation to bone health. Evid Rep Technol Assess (Full Rep) 2007,158:1-235.

57 Gordon CM, DePeter KC, Feldman HA, Grace E, Emans SJ. Prevalence of vitamin D deficiency among healthy adolescents. Arch Pediatr Adolesc Med 2004;158:531-7.

58 Prentice A, Parsons TJ, Cole TJ. Uncritical use of bone mineral density in absorptiometry may lead to size-related artifacts in the identification of bone mineral determinants. Am / Clin Nutr 1994;60:837-42.

59 Cohen J. Statistical power analysis for the behavorial sciences. Lawrence Erlbaum, 1988.

Accepted: 22 November 2010 